\title{
From Riot Grrrls to roller derby? Exploring the relations between gender, music and sport
}

The current revival of the sport of roller derby was initiated in 2001 by members of the Riot Grrrl movement in Austin, Texas. Since then, the sport has grown rapidly across the globe. In roller derby, style, costume and attitude are integrated with skills, embodied competencies and fitness, providing an example of the tensions between creativity and constraint that are possible within sport. From its direct links to DIY punk and the Riot Grrrl movement through to the more implicit links to improvisation and competence, roller derby provides a space to explore some under-acknowledged connections that exist between sport and music. This article argues that roller derby enables women to experience a creative, gendered leisure space in which music, play and competitive sport come together, with women placed at its centre. Using my own experiences as a new roller derby participant, as well as observations of popular discourses about roller derby, this article outlines the ways in which sport and music are related, allowing women to shift between multiple subject positions not previously available to them, as well as highlighting directions for future research.

\section{Introduction}

[It] is mathematics and music that create the smoothest of the smooth spaces. (Massumi, in Deleuze and Guattari, 1993 [1987]: xiii) 
Roller derby started in the late 1920s in the United States, and since then it has been transformed, revived, has disappeared and has now been revitalised in its current form. It is often discussed as a Do-It-Yourself (DIY), Riot Grrrl ${ }^{1}$ inspired, grassroots sport for women (see Finley, 2010; Storms, 2010), commonly found in the United States, the United Kingdom, Canada, Australia and several European countries, with new leagues steadily having formed across the globe since 2001. Roller derby integrates style, costume and attitude with skills, embodied competencies and fitness, and provides women with a creative space in which they can play with their identities, positioning them at the centre. Originally, when the sport was first popular between the 1940s and 1970s (Mabe, 2008), roller derby was more akin to the spectacle of wrestling. However, the new, revived version of roller derby promotes its empowering and inclusive qualities alongside the ‘tough' image of the previous mode of play. As roller derby is a contact sport, injury is quite common - indeed, this potentially dangerous aspect of the sport is a key part of its challenge and excitement. Yet many other aspects of the experience come together to make up the culture that is collectively named 'roller derby'. In particular, the current version of roller derby has very strong links to particular music genres: rockabilly, rock, punk and metal. These links with popular culture and the corporeal aspects of the scene - with women's bodies being very much at the centre of the sport - mean that analysing roller derby is a complex exercise.

\footnotetext{
${ }^{1}$ The Riot Grrrl movement started about 1992 and emerged from the punk and independent music communities of Olympia, Washington and Washington State in reaction to the misogynist tendencies of hardcore and punk scenes in the US. See work by (Piano, 2003; Rosenberg \& Garofalo, 1998; Schilt, 2004) for a more detailed account of the riot grrrl movement in the US.
} 
This article argues for understanding roller derby as a creative, gendered leisure space; an enabling space where it is possible to play with subjectivities and collective belonging. In roller derby, alternative subjectivities are expressed through popular music and style, allowing women to experience themselves as strong, tough and desirable. Using my own experiences as a new roller derby participant in Australia, as well as observations of popular discourses about roller derby, this article outlines the ways in which sport and popular music are linked, and how these links allow women to shift between multiple subject positions not previously available to them. I will argue that both the musical context and physical aspects of roller derby allow women to experience themselves differently, affording them to enrich their subjectivities through the styles and attitudes of various genres of music, along with the body capacities roller derby requires.

The cultural context for this article is the roller derby scene in Australia where over 50 leagues have been established since around 2003. With over 200 leagues worldwide ${ }^{2}$, Australia hosts a relatively large proportion of thesemostly situated on the East coast, mainly in and around major cities, although there are several regional and rural leagues that have started up more recently. Each league develops between two to four teams, which then train together and

\footnotetext{
${ }^{2}$ See the International Roller Girls' Master Roster, www.twoevils.com for a list of all players and leagues around the world. Currently there are over 26,857 players registered worldwide (at July, 2011).
} 
compete against each other. Although the overall goal is to win, there is a real focus on fun, expression and style. Roller derby provides an alternative leisure space for women to use their bodies differently, and it allows multiple subject positions to be explored. Work by leisure studies researchers such as Wearing (1998) and Aitchison (2003) has demonstrated the value of exploring women's leisure from a feminist, post-structuralist perspective. Such an approach enables a more nuanced investigation of a sport such as roller derby that women are using in a range of ways towards alternative expressions of the self and of being female. As a high-impact sport, roller derby clearly 'creates spaces for the transmission and confrontation of cultural values, especially with regard to gender' (Wearing, 1998, p. 80). In this article I am interested in providing new insights into women's leisure, and in particular in how roller derby brings sport and music together in a creative leisure experience.

\section{Music, sport and subculture}

In starting to think about the relations between popular music and sport, Bennett finds that 'there are clear, if under-acknowledged, continuities between musical taste and extreme sports', and that significant gaps in the literature exist in this area (Bennett, 2005, p. 340). McLeod (2006) theorises the relationship between sport and popular music, noting how both sport and music allow individuals to 'assert their excellence as soloists while remaining part of a cohesive group’ (2006, p. 532). While Rowe (1995) also writes about both sport and music, he does not explore the relations between them in popular culture, although he does notice how sport can be more resistant to forces of globalisation than music (Rowe, 2003). 
Within the leisure studies field, Caudwell (2010) writes of how in jazz music, as in sport, improvisation is seen as a form of gendered, embodied reflexivity, portrayed as 'natural', 'impulsive' and 'unrehearsed'. However, that such comparisons between popular music and sport are rare within the literature points towards the rich theorising still to be done in this area. Further, much of the writing on leisure and subcultures does not take into the account the gendered nature of leisure and new developments in theory on affect and affiliation (see for example, Atkinson \& Young, 2008). In this article I bring gender to the fore in thinking through the breakdown of the sport/culture binary.

Roller derby seems to provide women with something new, something that positively invigorates feminist debate and gives women a space of their own in which to experience the confidence and enjoyment that comes from leisure. There is a growing, albeit limited, literature on roller derby and how the sort makes alternative identities available to women (Carlson, 2010; Finley, 2010; Storms, 2010). However, as Carlson (2011) noted during her four months of participation in a league in the US, despite the opportunities for women to embrace aggression and remake femininity, there are ongoing tensions in roller derby about issues of athleticism and feminine subjectivity. My own observations reinforce Carlson's. To help me explore these tensions, I have turned to some of the literature focused on the music scene, where there have long been similar issues about how women might embody strength, aggression and femininity in creative performance and in managing creative careers. 


\section{Music scenes, Riot Grrrls and roller derby}

Peterson and Bennett (2004) discuss translocal music scenes, referring to 'widely scattered local scenes drawn into regular communication around a distinctive form of music and lifestyle' (2004, p. 6). As well as 'face-to-face' events, regular contact and 'scene' activity are undertaken between events via the internet: forums, blogs, zines ${ }^{3}$, Facebook and other websites. Because most roller derby leagues in Australia are resistant to coming under a governmentfunded body and place an emphasis on remaining 'independent', and are therefore resistant to formalising their structure, the analytical frameworks developed in relation to 'scenes', though originally used to talk about music scenes, is well suited to this discussion of roller derby. The scenes perspective allows a sense of movement and fluidity to be emphasised rather than structure and formality. Just as music festivals are a type of translocal scene (Peterson \& Bennett, 2004, p. 9), we can see national roller derby events such as 'The Southern Slam' in Australia and 'Roller Con ${ }^{, 4}$ in the United States in much the same way, as:

large, multiday events that periodically bring together scene devotees from far and wide where they can enjoy their kind of music [and sport] and briefly live the lifestyle associated with it with little concern for the expectations of others. (Peterson \& Bennett, 2004, p. 10)

\footnotetext{
${ }^{3}$ Zines are magazines produced by members and fans of a scene, usually with original content and with a very small circulation.

${ }^{4}$ http://greatsouthernslam.com.au/

http://rollercon.net/
} 
As a specific, gendered music scene, the Riot Grrrl scene has much continuity with the current form of roller derby. The Riot Grrrl movement started around 1992, emerging from the punk and independent music communities of Olympia, Washington and Washington, DC. 'Riot Grrrl encouraged women and girls to take control of the means of cultural production' (Schilt, 2004, p. 115) and become producers of music and zines, putting their own experiences at the forefront. It began as a local scene, an alternative to the more violent and misogynist tendencies growing within the punk scene at the time, but due to the distribution of zines and the formation of networks around the country, it quickly grew. This growth, though welcomed by Riot Grrrl members, raised challenging questions about how local music scenes can negotiate the various pressures on them. It is a familiar popular cultural circuit involving 'the desire to remain true to the original, local form of the scene and the pressure to expand, grow, and become more inclusive in order to allow the scene to thrive with new participants' (Schilt, 2004: 116).

This desire to remain 'true to the original' is ever-present within roller derby, and is a sticking point for many decisions, from uniforms/costumes and name choices to rules, organisational structure, music played, and so on. Although there is a 'local' flavour within each roller derby league, there is still a strong insistence on keeping as close to the 'original' as possible. This insistence on originality and 'authenticity' is highlighted within roller derby communities worldwide by the slogan 'by derby for derby', or 'derby owned, derby run' found on league websites and touted by small enterprises growing up 
alongside roller derby leagues ${ }^{5}$. Even the largest roller derby governing body, the Women's Flat Track Derby Association, states that, 'the governing philosophy of the WFTDA is "by the skaters, for the skaters"' (Women's Flat Track Derby Association, n.d.).

Along with challenges about authenticity, the Riot Grrrl scene experienced many other internal tensions, such as the question of whether the scene was about music or politics:

Musicians involved in the scene began to see themselves as being asked to delineate themselves as feminists who supported all girls' individual issues, rather than as musicians who had a serious interest in making music, a choice that many participants were resentful at being expected to make. (Schilt, 2004, p. 122)

This issue is similar to current tensions between the 'sport' of roller derby and the spectacle, discussed in many blogs and league websites ${ }^{6}$. Piano (2003), writing on the Riot Grrrls, observes that "it is in 'doing' (making zines, playing in bands, reading zines, organising conferences) rather than in 'being' (viewed as a spectacle) that participants become group members, and consequently,

\footnotetext{
${ }^{5}$ See the following websites for examples of this discourse, http://sydneyderbyskates.com/shop/; http://www.derbyowned.com/the-list/39-retailsporting-goods-roller-skates-and-gear/89-bruised-boutique-skateshop,

${ }^{6}$ See the following websites for good examples of the way this tension is framed by members of the roller derby community, http://derbywannabe.wordpress.com/2011/02/16/rollerderby-sport-or-theatre-aesthetics-vs-athleticism/, http://fiveonfivemag.com/issues?page=2, http://bitchmagazine.org/article/holy-rollers
} 
where the potential for political intervention and group affiliation can take place” (Piano 2003: 254). Within roller derby, it is definitely 'doing' that is privileged, with many leagues outlining strict codes for volunteering, participation and league activity (for example, see Newcastle Roller Derby, n.d.; Victorian Roller Derby League, n.d.) ${ }^{7}$. This 'doing', though actively encouraging women to become producers, means that many women are excluded, either because of other commitments (such as child care), other interests, or a desire to participate more casually.

Yet there are other ways of 'doing', explicitly linked to music and style, which make other subjectivities available to women - subjectivities that may not be overtly political, but are important nonetheless. Piano notes that 'style has ... become a site in which to contest dominant representations of women’ (2003, p. 257). It is this move away from overt politics and towards style and affective relations that becomes important within roller derby as it continues to grow as a sport and leisure activity for women (see Clough \& Halley, 2007 for an overview of the 'affective' turn within cultural theory). As well as toughness, physical ability and actual time volunteered within their league, style, fashion and visual aesthetics are important ways in which women identify themselves as part of the roller derby community. This multiple focus of identity in some ways challenges traditional notions of sport and femininity.

\footnotetext{
${ }^{7}$ See league websites for more detailed information on these policies and discourses, for example: http://www.newcastlerollerderby.org.au/, http://www.perthrollerderby.com.au/official-documents, http://www.nwarollerderby.com/fresh-meat/, http://applecityrollerderby.com/Volunteer\%20of\%20the\%20Month.html
} 


\section{Subverting sport and disrupting femininity}

Research consistently shows that women participate less in physical activity than men, particularly as they get older (Australian Bureau of Statistics, 2006). Yet roller derby, as a sport aimed specifically at women ${ }^{8}$, is attracting a wide range of women of various ages and skills. Exploring alternative feminine subjectivities and experiencing feelings of empowerment are common within non-traditional ${ }^{9}$ leisure spaces (Atencio, 2008; Atencio, Beal, \& Wilson, 2009; Wearing, 1998). However, these feelings of empowerment are not necessarily a resistant movement. It is here, in leisure, that women can structure their subjectivities and adopt practices that represent both conformity and resistance to dominant power and discursive relations (Atencio, 2008, p. 323).

Given their resistance to external organisation or structuring by governing bodies and therefore also to various forms of standardisation in style, the current conditions of roller derby allow women to parody hetero-normative gender relations. This is evidenced by the often overtly sexualised costumes commonly worn - such as fishnet stockings and garter belts - and the outrageous names used, such as 'Storm in a D Cup' and 'Annibella Apocalipstick' (see www.twoevils.org for the complete list). It also gives women the opportunity to practise what has been called 'gender manoeuvring', where they take cultural content from one context and move it into another, thus

\footnotetext{
${ }^{8}$ Men play mostly supportive roles as referees and coaches, although a small number of male teams are starting to promote themselves

${ }^{9}$ By non-traditional, I refer to those sports and leisure activities often labelled 'alternative', 'extreme', 'lifestyle' or 'non-mainstream' within the literature.
} 
disrupting the norms of gender and creating alternative gender relations (Finley, 2010, p. 362).

Roller derby presents a paradoxical opportunity for women to explore the multiplicities of their embodied selves, in a space where they can use their bodies in risky ways, breaking with tradition and experiencing themselves as different to the hetero-normative representations of women commonly found in mainstream sports and music. Through the use of force - as in bodily force in a roller derby bout ${ }^{10}$, and their personal force as assertive and tough - women can explore the multiple subjectivities available to them. As recognised by Massumi:

Force is not to be confused with power. Force arrives from outside to break constraint and open new vistas. Power builds walls. (in Deleuze \& Guattari, 1987, p. xiii).

As Wearing states, 'resistance is a strategy where deployment of power is the aim rather than revolution and the false promise of liberation' (1998, p. 146). Through the women's bodily force, they break open new horizons for themselves.

\section{A creative gendered leisure space}

I went to Sydney, Australia, to watch a bout and was bedazzled by the spectacular pre-game show. As the lights dimmed, the 4,000-plus audience quietly watched as a lone skater came out on to the track, which was lit only in the middle. This skater, wearing a blonde wig and pink dressing gown, swayed to and fro while looking at herself in the

\footnotetext{
${ }^{10}$ Roller derby games are called 'bouts'.
} 
makeshift mirror, as the lyrics to Doris Day’s 'Que Sera Sera’ were played over the speakers:

'When I was just a little girl, I asked my mother, what will I be Will I be pretty, will I be rich? Here's what she said to me:

'Que sera, sera, Whatever will be, will be, The future's not ours to see, Que sera, sera.’

Then the music began to change. It got louder, and faster. Then a hard, driving beat was played on top of the song, until you could no longer hear it at all. Now all that could be heard was the sounds of heavy guitars and loud drums as the first team rolled out from backstage on to the track and through the 'mirror', taunting the girl with the pigtails and pink dressing gown. (Researcher’s field note, 26 June 2010)

This use of music to signify roller derby is common, and the 'roll out' the way the team comes out on to the track - is an important part of the sport. This is where the women show themselves as tough and skilful, with the music highlighting these qualities. AC/DC's 'Thunder Struck', Peaches' 'Boys Want to Be Her' and The Ramones, 'Sheena is a Punk Rocker' are examples of songs used for the all-important 'roll out' at roller derby bouts. My case note above 
shows how one league used popular music to show the different subject positions that roller derby provides for women: the roller derby grrrl - tough, mean, skilful and unintelligible to the girl with the pigtails who she taunts provides an alternative to the young, slim girl dressed in pink and worrying about her future. Roller derby grrrl was not an option to choose from when she looked in the mirror and imagined her gendered future. The roller derby grrrls presented in this instance were all different ages, shapes and sizes, and although the majority of them were white, there were several other ethnicities represented in the teams, including Asian ${ }^{11}$ women; some women also wore dark face paint, hiding their whiteness.

Through the force of the music played at roller derby bouts, new possibilities are also generated. These possibilities are not infinite and there is a privileging of rock music by male artists which would have implications for the types of subjectivities available to women. Nonetheless, a space is created where tough, strong women interact with each other, and where these women are revered for their skill and performance without being compared with male counterparts.

In her comparative discussion of jazz and sport, Caudwell (2010) argues that 'the dominant improvisatory-aesthetic is contingent on gender and

\footnotetext{
${ }^{11}$ In the context of Australia and the US, the term Asian refers to people from East Asian and South-East Asian countries (for example, China, Vietnam, Korea, Thailand), whereas in the UK, Asian refers to people mainly from South Asia (particularly India and Pakistan). In this instance the author uses the Australian/US version of the term. The majority of the roller derby players observed have been white and the use of dark face paint poses problematics and potentials that are beyond the scope of this current paper.
} 
sexuality' (2010, p. 240). Her popular cultural analysis stresses metaphor and music, and provides a lead for my own analysis of culture and sport. Although she doesn't mention it, I am reminded of Lyng's concept of edgework, where the skills are regarded 'as non-cognitive and fully embodied in nature' (Lyng, 2008) and where flexibility - 'the ability to ad hoc a response and avoid crossing the line between order and disorder' (Lyng, 2008, p. 89, italics added) - is imperative. Caudwell shows how in jazz music, as in sport, improvisation in these fields is portrayed as 'natural', 'impulsive' and 'unrehearsed' (2010, p. 244). For Caudwell, women musicians and sports women negotiate 'the limits of intelligibility' through a focus on interactivity, and the sensory and creative aspects of both sport and music (2010).

Wearing notes that 'pre-AIDS, and before any specific challenge to the romantic discourse, jazz and the jazz dance can be seen ... to shift women's subjectivities beyond the prevailing norms of the times' (1998, p. 69). In both sport and jazz, it is the figure of the masculine subject who represents the 'normal' player. Jazz has had a long history of subverting societal norms and discourses, while in roller derby women are positioned on their own terms, providing an opportunity for them to create themselves as intelligible subjects in new ways. As a sport with strong links to popular music and other cultural forms, roller derby provides one field in which affective, interactive and sensual aspects of experience are privileged ${ }^{12}$.

\footnotetext{
${ }^{12}$ Although not always the case, some of the music played at roller derby bouts and revered by roller derby players is by women. These all female rock bands often use explicitly feminist lyrics with the rhythms and riffs of traditional masculine rock, in a way 'reworking' rock and sport.
} 
Roller derby - the sport as well as the events and community growing up around it - re-centres both the body and music, as well as style and collective association, in a way that neither sport nor popular music has done before. Sports like skateboarding and snowboarding have brought some of these aspects together (Beal, 1999; Borden, 2001; Thorpe, 2005), but are altogether different from roller derby in that they are not team sports. Most importantly, they do not place women at their centre. Roller derby is therefore a team sport that has style, music, collective identity and the female body at its centre. It is regulated - with formal membership to a league dependent on the development of certain skills and bodily aptitudes and the payment of league membership - while at the same time being fluid. Looking closely at the women at practice, one starts noticing the differences between them. Some wear heavy metal t-shirts, while others wear fishnets and sparkly adornments; some wear heavy make-up to training, others wear none at all; some are heavily tattooed, and others have no visible tattoos, and so on.

Wearing writes that 'leisure spaces (heterotopias) for women provide spaces for rewriting the script of what it is to be a woman, beyond definitions provided by powerful males and the discourses propagated as truth in contemporary societies’ (1998, p. 147). Roller derby, as a space distinctively different from work, child care and even other women’s sports such as netball, is a leisure space where the macro and the micro levels of identity can be played with. Roller derby allows women to question what it means to be a woman and what women's leisure should be. 
Although roller derby challenges cultural hegemony, there are internal dynamics that trouble the sport. Tensions exist over the place of music and style, for example. As a type of 'neo-tribe ${ }^{, 13} /$ translocal scene, roller derby presents a leisure space free from some of the constraints of the world of work. However, unlike the Riot Grrrl movement, roller derby appears to be here to stay, for the medium term at least. This being the case, the inherent tensions within the scene need to be explored and somehow addressed, without negating the sensual, feminine aspects of the sport and its strong links to music and style. Within some leagues, there is already a push away from the affective aspects of the sport towards a more traditional sports structure. However, the relationship with music and style remains an important element of roller derby, one that has been part of the sport since its reinception in early 2001.

As a 'non-traditional'/alternative sport, roller derby differs from most other expressions of community due to the special significance of 'affect to the central enterprise of the collectivity' (Lyng, 2008, p. 104) as a defining aspect of belonging. Roller derby participants must confront and manage fear, uncertainty, feelings of omnipotence and pain - emotions that most other communities do not face on a regular basis. Lyng (2008) argues that these affects are some of the most unifying experiences in extreme sports communities. In roller derby, there is always a risk that you will hurt your teammate, yet it is this possibility that turns some women on to the sport, with several women in my research stating that they wanted to 'hurt people' and that their desire for aggression was a major factor in their participation. These

\footnotetext{
${ }^{13}$ See work by (Maffesoli, 1996) and (Bennett, 1999)
} 
qualities - often attributed to masculinity - are sometimes reflected in the music associated with roller derby, with its strong emphasis on heavy rock and 'hard' music. In roller derby movement and force are privileged above passivity.

\section{'Jamming' 14}

The focus on movement and action, made explicit in roller derby on the track but implicit in the organisation of the sport, could be one of its greatest strengths. Eisenberg (1990) talks of philosophical accounts of the 'death of man':

With the demise of 'man' as omnipotent subject and personalised repository of meanings, one consequence is that humans will have to learn more about surrender, in order to better live with the flow. (1990, p. 156)

For roller derby, at least, this demise of 'man' is perhaps the birth of 'woman' as alternative subject, and as alternative organisational body that can guide and support roller derby and the multiple ways of being it makes possible. Music and the arts were traditionally placed in dichotomous opposition to sport and action, with the arts being related to women and sport to men. In roller derby, these distinctions no longer apply, and 'jamming' can occur between these two conventionally binarised spaces.

The tensions between autonomy and interdependence, cooperation and competition, the arts and sport, and so on, are 'at the heart of all social

\footnotetext{
${ }^{14}$ Drawing from the concept of 'culture jamming' used in art and cultural theory, see for example (Carducci, 2006; Darts, 2004; Harris, 2004).
} 
organisation[s]' (Eisenberg, 1990, p. 143). Discussing the links between sport and music, Eisenberg (1990) highlights the concept of 'jamming'. He shows how disclosure and intimate personal relationships have become more important in recent years than the results of people's actions. This focus on the private realm is akin to ideas around the 'biographical turn' (Thomson, 2007), where disclosure and stories about the self are privileged and become a central focus for the creation of the self. For organisations, this has meant privileging shared values and personalities over action and diversity. Eisenberg (1990, p. 160) argues for a different type of relationship:

Jamming is a third ideal type of relationship; between the cold nondisclosive relationship and the intimate disclosive one lies the close, nondisclosive relationship rooted in collective action. Jamming stresses coordination of action over the alignment of cognitions, mutual respect over agreement, trust over empathy, diversity over homogeneity, loose over tight coupling, and strategic communication over unrestricted candor.

This focus on nondisclosive, action-orientated relationships is articulated by Eisenberg (1990) through his experiences as a basketballer and musician, which for me also recalls Caudwell's (2010) jazz-sport analogy. As it happens, roller derby consists of numerous 'jams', where each team has its 'jammer', with the goal of trying to pass as many of the opposing team's 'blockers' as possible. This discursive coincidence and link to jamming could be a telling indication of the women's desire to take their cultural and subjective expressions in a new 
direction - moving away from a central focus on intimate relationships and shared values and motivations, towards instead strategically privileging movement and uncertainty.

\section{Conclusions}

This article has argued for roller derby as a sport and creative leisure practice; an enabling space where female subjectivities and collective belonging can be played with. Roller derby's growing popularity - as evidenced by the number of leagues being established and the number of names being registered with the international names register - highlights the need for further understanding of the dynamics of this complex leisure activity. Primarily a women's sport, roller derby presents an opportunity for women to position themselves as intelligible subjects, capable of complex and at times dangerous improvisation. Roller derby privileges the affective, sensual aspects of leisure and its focus on music as part of a creative assemblage with style allows women to become empowered and to challenge hetero-normative gender roles. In the popular literature about roller derby, the sport is explicitly linked to music, be it punk rock, rockabilly or rock. Joulwan (2007), who was part of the initial roller derby revival in the United States, goes so far as to outline her 'derby playlist', stating 'it's a mix of songs that I associate with being powerful, aggressive and sexy - the emotions I try to channel when I hit the track’ (2007, p. 153).

By privileging music within sport, roller derby allows women to play with their multiple subjectivities. In writing about music, Deleuze and Guattari 
state that 'in a smooth space-time one occupies without counting, whereas in a striated space-time one counts in order to occupy' (1987, p. 477). At present, space in roller derby is smooth. It is a space where music and sensuality are privileged over structure and routine; however, as Deleuze and Guattari observe, 'smooth space will [not] suffice to save us' (1987, p. 500). As an empowering space for women, roller derby eventually will become striated evidence of this is found in the way roller derby leagues are beginning to structure themselves and the increased focus on the athleticism and seriousness of the sport. The more music and music cultures are pushed to the background within roller derby, the more this space will become striated. This is not to say that roller derby as a sport, without the music and music cultures currently associated with it, will not have benefits for women - the benefits of sports are well documented - but rather that the possibilities presented by roller derby for alternative subjectivities and transformation may be lost.

Music associated with roller derby is more aligned with the masculine cultures of punk and metal than the feminine 'bedroom' cultures written about by subcultural researchers such as McRobbie (1994). This 'hard' music allows the expression of emotions and styles that can in some ways challenge the normative construction of gender and femininity. The music relates to the game of roller derby itself, as a contact sport for women of all different body shapes. The relation of music and roller derby contributes substantially to the creation of the 'smooth space' of which Deleuze and Guattari (1987) speak - that space where time is suspended-a creative, gendered leisure space. However, just as smooth space can quickly become striated, so can the striated be reterritorialised 
by the disorganising qualities of the smooth. Like the Riot Grrrls scene, the intense growth of roller derby, along with the desire to remain true to the 'original' - without the 'original' ever really being articulated clearly - presents both theoretical and practical challenges for the sport and for any analysis of it. There are potentials for movements in several directions.

Extrapolating from Caudwell's (2010) work on music, gender and sport and Eisenburg's (1990) work on organisations and 'jamming', together with Deleuze and Guattari’s (1987) ideas about smooth and striated space, this article has started to uncover the theoretical and practical implications of the relationships between music and sport. These implications are for the individual and the collective, the roller derby player and her league, the sportswomen and her sport. The relationship between sport and music allows for alternative subjectivities and organisational forms to be played with/tried out/explored, and also allows for an alternative relation between women and leisure in general. Through music and a focus on the sensual and affective aspects of sport, and the improvisational qualities of jamming, women are intelligible, both as the 'main player' and as leaders within sports organisations.

Creative, gendered leisure spaces that incorporate athleticism with music and the arts, could be a new conceptualisation of women's leisure. As roller derby has been for many women, this leisure space could subvert, disrupt and ‘jam' the cultural hegemony found in many sports and leisure practices available to women. By breaking down binaries such as creativity and sport, movement and structure, feminine and masculine, a 'smooth' space is created 
where time can be suspended and women can experience positive transformation that may perhaps seep into other parts of their lives.

\section{References}

Aitchison, C. C. (2003). Gender and leisure: Social and cultural perspectives. London: Psychology Press.

Atencio, M. (2008). 'Freaky is just how I get down': investigating the fluidity of minority ethnic feminine subjectivities in dance. Leisure Studies, 27(3), 311-327.

Atencio, M., Beal, B., \& Wilson, C. (2009). The distinction of risk: Urban skateboarding, street habitus and the construction of hierarchical gender relations. Qualitative Research in Sport, Exercise and Health, 1(1), 320.

Atkinson, M., \& Young, K. (2008). Tribal play: subcultural journeys through sport (Vol. 4): Emerald Group Pub Ltd.

Australian Bureau of Statistics. (2006). National Centre for Culture and Recreation Statistics: Women's Participation in Sport and Physical Activities. Retrieved viewed 18 June 2010, from http://www.ausport.gov.au/_data/assets/pdf file/0007/276937/ABSwomens_participation_sport_physical_activity.pdf

Beal, B. (1999). An alternative to mainstream sports. In J. Coakley \& P. Donnelly (Eds.), Inside sports (pp. 133). London: Routledge.

Bennett, A. (1999). Subcultures or neo-tribes? Rethinking the relationship between youth, style and musical taste. Sociology, 33(3), 599.

Bennett, A. (2005). Editorial: popular music and leisure. Leisure Studies, 24(4), 333-342.

Borden, I. (2001). Skateboarding, space and the city: architecture and the body. Oxford: Berg Publishers.

Carducci, V. (2006). Culture Jamming. Journal of Consumer Culture, 6(1), 116.

Carlson, J. (2010). The female significant in all-women's amateur roller derby. Sociology of Sport Journal, 27(4), 428-440.

Carlson, J. (2011). Subjects of stalled revolution: A theoretical consideration of contemporary American femininity. Feminist Theory, 12(1), 75.

Caudwell, J. (2010). The jazz-sport analogue: Passing notes on gender and sexuality. International Review for the Sociology of Sport, 45(2), 240.

Clough, P. T., \& Halley, J. O. M. (2007). The affective turn: Theorizing the social. Durham: Duke University Press Books.

Darts, D. (2004). Visual culture jam: Art, pedagogy, and creative resistance. Studies in Art Education, 313-327.

Deleuze, G., \& Guattari, F. (1987). A thousand plateaus: Capitalism and schizophrenia. Minneapolis: University of Minnesota Press.

Eisenberg, E. M. (1990). Jamming. Communication Research, 17(2), 139.

Finley, N. J. (2010). Skating Femininity: Gender Maneuvering in Women's Roller Derby. Journal of Contemporary Ethnography, 39(4), 359. 
Harris, A. (2004). Jamming girl culture: Young women and consumer citizenship. In A. Harris (Ed.), All about the girl: culture, power, and identity (pp. 163-172). Milton Park: Routledge.

Lyng, S. (2008). Risk-taking in sport: edgework and reflexive community. In M. Atkinson \& K. Young (Eds.), Tribal play. Subcultural journeys through sport.

Mabe, C. (2008). Roller derby. The history and all-girl revival of the greatest sport on wheels. Denver: Speck Press.

Maffesoli, M. (1996). The time of the tribes. London: SAGE Publications.

McLeod, K. (2006). "We are the Champions": Masculinities, Sports and Popular Music. Popular Music and Society, 29(5), 531-547.

McRobbie, A. (1994). Postmodernism and popular culture. London: Routledge.

Newcastle Roller Derby. (n.d.). Code of conduct. Retrieved 28 October, 2010, from

http://newcastlerollerderby.org.au/e107_files/downloads/NRDL_Code_o f_Conduct_29-01-09[1].pdf

Piano, D. (2003). Resisting Subjects: DIY Feminism and the Politics of Style in Subcultural Production. In D. Muggleton \& R. Weinzierl (Eds.), The post-subcultures reader. Oxford: Berg.

Rosenberg, J., \& Garofalo, G. (1998). Riot grrrl: Revolutions from within. Signs, 23(3), 809-841.

Rowe, D. (1995). Popular cultures: rock music, sport and the politics of pleasure. London: SAGE Publications Ltd.

Rowe, D. (2003). Sport and the repudiation of the global. International Review for the Sociology of Sport, 38(3), 281.

Schilt, K. (2004). " Riot Grrrl Is...": The Contestation over Meaning in a Music Scene. In A. Bennett \& R. A. Peterson (Eds.), Music Scenes: Local, Translocal, and Virtual (pp. 115-130). Nashville: Vanderbilt University Press.

Storms, C. E. (2010). There's no sorry in roller derby: A feminist examination of the collective identity formation of women in the full contact sport of roller derby. New York Sociologist, 3, 68.

Thomson, R. (2007). A biographical perspective. In M. J. Kehily (Ed.), Understanding youth: perspectives, identities and practices. London: Sage.

Thorpe, H. (2005). Jibbing the gender order: Females in the snowboarding culture. Sport in Society, 8(1), 76-100.

Victorian Roller Derby League. (n.d.). Welcome to roller derby. Retrieved 28 October, 2010, from http://www.skatevictoria.com.au/rollerderby.html

Wearing, B. (1998). Leisure and feminist theory. London: Sage Publications Ltd.

Women's Flat Track Derby Association. (n.d.). Home page. Retrieved 31 August, 2010, from www.wftda.com 